\title{
Mídia e Educação - Resgate da Produção Acadêmica em Cursos de Pós-Graduação Brasileiros (2005-2009)
}

Fernando Teixeira

Vivian Leyser da Rosa

\section{Resumo}

O campo das relações entre mídia e educação é fértil em discussões que permitem visualizar novos caminhos para seu mútuo desenvolvimento, bem como de tendências epistemológicas que as caracterizam. $O$ presente artigo expõe e discute um levantamento das produções acadêmicas (na forma de teses e dissertações) que tratam de tais relações, produções estas realizadas no período de 2005 e 2009. Foram analisados trinta e dois estudos, dos quais são apresentadas suas principais características, incluindo objetivos, metodologias, resultados e referenciais teóricos utilizados com maior freqüência por seus autores. $\mathrm{O}$ quadro assim composto permite identificar as principais tendências das investigações no campo, bem como sinalizar possibilidades para futuros estudos.

Palavras-chave: mídia, educação, educação para os meios, educomunicação, educação e mídia.

\section{Abstract}

Media and Education - an Overview of Academic Production in Brazilian Masters and Doctorate Degree Courses (2005-2009)

Studies on the relationship between media and education are a fertile field of discussions, pointing to new paths for their mutual development, as well as to trends that shape their epistemological views. This paper presents and discusses a review of recent Brazilian academic production (theses and dissertations) dealing with such relations, between 2005 and 2009. Thirty two studies were analysed and their main characteristics, objectives, methodologies, results and theoretical 
frameworks are here presented. Such a review allows us to identify main investigation trends in the field, as well as a number of possibilities for future studies.

Keywords: media, education, education for the means, educommunication, education and media.

\section{Introdução}

A mídia vem exercendo, atualmente, um importante papel na educação, seja esta entendida através de seus modelos formais ou mesmo a que se processa de maneira informal. As relações entre estes dois campos já constituem, há algum tempo, num importante tema de discussões acadêmicas, fato este atestado pelo significativo volume de produções que objetivam conhecer e aprofundar os meandros e as possibilidades de tais aproximações.

No presente artigo, busca-se oferecer um panorama geral dessas produções, desenvolvidas na forma de dissertações e teses em cursos de pós-graduação de universidades brasileiras, no período recente de 2005-2009. Pretende-se, desta forma, descrever o que pensam os pesquisadores sobre a área em discussão, como percebem sua evolução e como se processa sua aplicação no contexto escolar.

A revisão aqui apresentada teve como base de consulta a Biblioteca Digital Brasileira de Teses e Dissertações (BDTD), do Ministério da Ciência e Tecnologia do Brasil, e a Biblioteca Digital de Teses e Dissertações da Universidade de São Paulo - USP. Para realizar a busca, foram utilizadas as seguintes palavras-chave: mídia e meio ambiente, mídia e meios de comunicação, educação para os meios, educação e mídia, e educomunicação.

Foram localizados inicialmente quarenta trabalhos, entre teses e dissertações. Após análise mais detalhada dos respectivos resumos, em que se buscou uma maior aproximação com o foco da pesquisa, foram selecionados trinta e dois trabalhos, realizados em nove universidades do país. A Tabela 1 mostra os acervos onde estas pesquisas foram localizadas, bem como sua distribuição conforme o nível de titulação.

Tabela 1 - Localização das teses e dissertações pesquisadas.

\begin{tabular}{c|c|c|c}
\hline Tipo de Trabalho & \multicolumn{2}{|c|}{ Localização } & \multirow{2}{*}{ Total } \\
\hline \multirow{2}{*}{ Dissertações } & BDTD & Biblioteca Digital USP & \multirow{2}{*}{26} \\
\cline { 2 - 3 } & 14 & 12 & 06 \\
\hline Teses & 02 & 04 & 32 \\
\hline Total & 16 & 16 & \\
\hline
\end{tabular}


Para que se possa visualizar as características de cada um destes trabalhos, bem como a evolução e a pertinência dos temas ao longo do período pesquisado, as teses e dissertações são apresentadas a seguir, em ordem cronológica e conforme os seguintes focos temáticos: educação para a mídia; educomunicação pelo rádio; utilização de recursos vídeo- tecnológicos na educação; utilização da internet nos processos educativos; o meio ambiente na mídia; ciência e tecnologia na mídia, e educação nos meios de comunicação.

\section{Educação para a Mídia}

Em 2007, foi apresentada ao Curso de Pós-Graduação em Educação da PUC-PR, por Laurete Maria Ruaro, a dissertação Educação para e com a mídia - análise da utilização das tecnologias da informação e comunicação na rede pública de educação: Programa Paraná Digital.

O trabalho empreendeu uma análise do fenômeno informacional e comunicativo no interior do espaço educacional, procurando entender a postura docente quanto à utilização e exploração das tecnologias como ferramentas didáticas capazes de fomentar prazer e estímulo à pesquisa, e de como estas podem ser utilizadas de forma consciente e produtiva em processos de ensino-aprendizagem. Investiga a inclusão das TIC (Tecnologias de Informação e Comunicação) no espaço escolar, observando as variáveis históricas, políticas e culturais que o permeiam, pontuando o comportamento do professor frente à organização de novas tecnologias, a fim de suprir a demanda tecnológica/escolar vigente. Neste trabalho foram consideradas, analisadas e relatadas algumas experiências, de modo a contribuir para a elaboração e implementação de abordagens educacionais mais significativas quanto à possibilidade de utilização das TIC, visando processos de ensino/aprendizagem mais colaborativos, interativos, reflexivos e humanos.

A pesquisa, realizada com quarenta e dois professores de ensino fundamental e médio de um Colégio Estadual da cidade de Guarapuava, Paraná, também utilizou informações referentes à proposta do Estado do Paraná, para a inserção das TIC em ambientes escolares.

Os referenciais de autores como Pierre Lévy, Kevin Mcgarry, Maria Luiza Belloni, Marilda Behrens, José Moran e Paulo Freire, bem como uma pesquisa de campo, desenvolvida com professores, permitiram diagnosticar um grande déficit no emprego dos recursos tecnológicos de informação e comunicação, na organização do trabalho pedagógico.

O trabalho sinaliza para o uso não-efetivo das TIC em sala de aula e conclui que isto ocorre não por falta de oferta dessas tecnologias na instituição, mas sim devido ao despreparo dos profissionais para integrá-las ao seu cotidiano, como um diferencial em relação às aulas expositivas. Indica-se ainda que sua inclusão no espaço escolar esbarra na resistência em banir 
métodos escolares tradicionais, pois, a partir da possibilidade da inserção dessas novas tecnologias, há necessidade de redimensionamento da práxis educativa, medida que exigiria um profundo processo de reconstituição dos conceitos de escola, sociedade, aprendizagem e do profissional da educação. A autora destaca ainda que, através da inserção de um Programa de inclusão digital desenvolvido pelo governo do Paraná, surge uma tentativa, naquele estado, de se redimensionar o trato das informações veiculadas pela mídia, promovendo a democratização do acesso à comunicação.

Em 2008, Laura Seligman defendeu, junto ao Programa de Mestrado Acadêmico em Educação da UNIVALI-SC, a dissertação $A$ escola e a formação do leitor crítico da mídia: políticas públicas no Brasil e em Santa Catarina.

A pesquisa aprofunda a discussão sobre a relação entre sociedade e informação. Trata das diversas concepções de educação para a mídia e as denominações semânticas e conceituais nos diversos países que se dedicam a estudar este tema. Autores como Yonejí Massuda, Christopher May, Theodore Roszak, James Potter, Marshal Mcluhan, Mário Kaplun, Manuel Castels, Ismar Soares e Maria L. Belloni, compõem o referencial utilizado, para estudar as opções encontradas pelos educadores que pretendem se adequar a esta nova realidade educacional.

A autora lança três questões que norteiam sua pesquisa: Como os documentos públicos se referem à necessidade de educar para a alfabetização e leitura crítica da mídia? Como a educação escolar, principal ambiente de ensino e aprendizagem, deve se preparar para este processo de letramento para a mídia? Como o Estado, principal provedor da educação na sociedade brasileira, vem contribuindo para o aparelhamento tecnológico do sistema educacional?

Os documentos analisados visam compreender o que pensam e como agem os gestores da educação pública, quanto à inserção das novas TIC no espaço formal da educação. Estes documentos, reconhecendo a necessidade de se preparar as novas gerações para o uso adequado das TIC, apontam para a necessidade da imediata inserção das mesmas nos ambientes escolares. Entretanto, referem-se a elas apenas como ferramentas educativas, não explicitando recomendações para que possam ser utilizadas como elementos propulsores de uma educação para a mídia.

A pesquisa aponta ainda para a necessidade de maiores investimentos, tanto para a aquisição de recursos materiais, quanto para a formação de professores, visando sua atuação na área da educomunicação. A autora indica, como exemplo de sucesso e como modelo a ser seguido, o Projeto Educom.rádio do NCE/ECA/USP, realizado em parceria com a Prefeitura de São Paulo.

Neste mesmo ano, Marciel Aparecido Consoni defendeu, junto ao Programa de PósGraduação em Ciências de Comunicação da Escola de Comunicação e Artes da USP-SP, a tese Mediação tecnológica na educação: conceito e aplicações. 
O trabalho aborda a área de intervenção educomunicativa denominada de "Mediação Tecnológica na Educação" (MTE). Trata-se de uma das vertentes nas quais o campo da educomunicação se estrutura epistemologicamente e que se encontra em evidência, na atualidade, por conta da educação à distância. Oferece referências para compor um quadro conceitual significativo, apto a fornecer aporte epistemológico e modelos de educomunicação para serem analisados e discutidos por professores que atuam, ou que venham atuar, nesta área. Também indica materiais impressos (livros e periódicos) e documentos oficiais, emitidos por órgãos governamentais envolvidos nos projetos analisados (Educom.TV; Educom.Rádio e Educom Geração Cidadã) do NCE/USP. Entre os principais autores consultados para esta pesquisa, destacam-se Lev Vigotsky, Paulo Freire, Jesús Martin-Barbero, Guillermo Orozco-Gómez e Ismar Soares.

A investigação foi realizada em noventa e seis diretorias de ensino da Secretaria de Educação de São Paulo, abrangendo dois mil educadores envolvidos em projetos de extensão universitária, na modalidade de ensino a distância. Procura aclarar o conceito de MTE, ampliando e fortalecendo o quadro teórico que dá suporte à educomunicação. Alguns dos aspectos desenvolvidos foram: definir um sentido que legitime o uso da expressão TEM; contribuir para a definição do significado do verbo "mediar"; alinhar diferentes abordagens tecnológico-educativas, evidenciando suas relações históricas e epistemológicas; e compreender o processo histórico que originou as correntes contemporâneas de estudo e emprego da relação tecnologia-educaçãocomunicação.

O autor considera que a pesquisa auxilia na consolidação do campo da educomunicação, trazendo ganhos epistemológicos e contribuindo para o entendimento e o exercício da mediação tecnológica na educação.

Ainda em 2008, foi apresentada ao Programa de Pós-Graduação em Educação da UFSC-SC, a dissertação Mídia-Educação no contexto escolar: mapeamento crítico dos trabalhos realizados nas escolas de ensino fundamental de Florianópolis, de Silvio da Costa Pereira.

A pesquisa investiga as atividades de mídia-educação que vem sendo desenvolvidas em escolas de ensino fundamental, em Florianópolis. Foram contatadas cento e dezoito unidades das redes pública e privada, procurando-se identificar os trabalhos realizados nesta área e conhecer suas principais características. Deste total foram selecionadas três escolas, nas quais, através da aplicação de entrevistas e contatos pessoais, foram obtidos dados a respeito do uso, dificuldades e soluções relacionadas às atividades que utilizam mídias. $\mathrm{O}$ autor adota um referencial teórico que aborda a interface entre as áreas da educação e da comunicação, com enfoque para o campo da mídia-educação. Entre suas referências, destacam-se: Maria Luiza Belloni, David Buckinghan, 
Mônica Fantin, Paulo Freire, Mário Kaplún, Maria I. Lopes, Jesús Martín-Barbero, Guillermo Orozco-Gomés e Roger Silverstone.

O autor buscou estabelecer relações entre os resultados de sua pesquisa e a declaração de Grünwald (Unesco, 1982) sobre mídia-educação. Oferece ainda algumas recomendações, como a adoção de um conceito de mídia-educação que leve em conta fatores como a promoção e o acesso às mídias, a análise crítica das mensagens e o estimulo ao uso criativo das diversas mídias disponíveis, em ambientes de ensino. Também aponta para a necessidade de se integrar a mídiaeducação à formação inicial de professores, nela incluindo dimensões conceituais e conhecimentos práticos. Finaliza propondo que a formação continuada de professores seja feita para a mídia-educação.

Em 2009, Cecília Fernandes Baptistella apresentou ao Programa de Pós-Graduação em Educação da Faculdade de Educação da Universidade Estadual de Campinas-SP, a tese $A$ concepção de pais e professores sobre a educação para a mídia televisa na escola.

A autora aponta, como principal objetivo do trabalho, conhecer os hábitos televisivos de pais e professores, bem como suas idéias sobre a educação para a mídia televisiva na escola. Busca estabelecer, desta forma, algumas relações entre o modo de compreender a televisão e suas funções, tanto no contexto familiar como escolar. Procura identificar as principais dificuldades encontradas por pais e professores com relação à educação para a mídia televisiva, além de conhecer como seus entrevistados analisam o papel do estado, da família e da escola na melhoria dos conteúdos exibidos na televisão.

A pesquisa contou com a participação de cem pais, que possuíam filhos com idades entre seis meses e quatorze anos, matriculados ou não em instituições escolares do município de Americana - SP. Participaram também da pesquisa cem professores do ensino infantil e fundamental, da rede pública e particular do município. A autora utilizou como referenciais em sua pesquisa, Pierre Bourdieu, Guilherme Canela, Juan Delval, Vera M. Lopes, Jean Piaget, Muníz Sodré e Roger Silverstone.

Além de fornecer um panorama a respeito dos hábitos televisivos de pais e professores, aborda várias questões relativas à educação para a mídia, como a influência dos conteúdos televisivos sobre as crianças; a importância atribuída pelos pais à classificação indicativa dos programas; uma avaliação do papel governamental frente aos conteúdos exibidos; o papel da sociedade para a melhoria destes conteúdos, e as dificuldades encontradas pelos pais no controle dos filhos, quanto ao uso da TV. A pesquisa reforça ainda a importância da escola para a formação de usuários críticos da mídia.

Ainda em 2009, a tese Educação pelos meios de comunicação: produção coletiva de comunicação na perspectiva da educomunicação foi apresentada por Grácia Lopes Lima ao Programa de Pós-Graduação em Educação, da Faculdade de Educação da USP-SP.

R. B. E. C. T., vol 4, núm 2, mai./ago. $2011 \quad$ ISSN - 1982-873X 
O trabalho objetiva evidenciar a produção coletiva da comunicação, na perspectiva da educomunicação como sinônimo de educação pelos meios de comunicação. A autora argumenta que os processos de criação vivenciados em pequenos grupos, mais do que os produtos de comunicação que eles geram, podem contribuir para uma educação comprometida com a constituição de sujeitos autônomos. Neste sentido, aponta para a necessidade de considerar a produção da comunicação como direito humano, a ser exercido por todas as pessoas. Defende que as tecnologias e linguagens midiáticas devem ser utilizadas como instrumentos que possibilitem, aos envolvidos no processo de criação, reconhecerem-se nas próprias palavras e imagens que produzem. A autora buscou fundamentação nos estudos da educomunicação, do imaginário, da pedagogia libertária e da comunicação comunitária, apoiada em autores como Paulo Freire, Mário Kaplun, Ismar Soares, Cicília M. Peruzo, Marcos Ferreira Santos e Manoel Barros.

Utilizando como metodologia a pesquisa-ação, o trabalho conclui que os processos de produção coletiva da comunicação, na perspectiva da educomunicação, possibilitam o encontro entre realizadores e seu repertório cultural cotidiano. Informa que ações pautadas pela metodologia de projetos, como o "Cala-boca já morreu" do NCE/USP, que pressupõem a afirmação de vínculos de afetividade e livre expressão de seus membros, possibilitam o estabelecimento de relações solidárias entre pessoas. Ressalta ainda que projetos nesta perspectiva, contribuem para uma educação efetivamente comprometida com o fortalecimento tanto dos indivíduos como dos grupos onde estes se desenvolvem.

No mesmo ano, Juliana Maria de Siqueira apresentou, ao Programa de Pós-Graduação em Ciências da Comunicação da USP-SP, a dissertação Quem Educará os Educadores? A educomunicação e a formação de docentes em serviço.

A pesquisa está situada no campo denominado de educomunicação, que permeia as áreas da Comunicação e da Educação, assumindo o compromisso ético e político com a construção da autonomia dos sujeitos no processo educativo, e apoiando-se nos conceitos de reflexibilidade e profissionalização, bem como na abordagem social da formação de professoras. Objetivou analisar as possibilidades e os limites da formação continuada de educadoras para a transformação da prática pedagógica, em direção à incorporação crítica das linguagens e dos discursos midiáticos.

No plano teórico, o estudo buscou discutir as possibilidades de se construir uma metodologia de pesquisa transdisciplinar para o campo da educomunicação, desenvolver uma abordagem educomunicativa na formação de educadores em serviço e analisar os pressupostos teóricos e metodológicos para a implementação de cursos de formação continuada, voltados a pratica educomunicativa. Utilizou como referenciais teóricos Theodor Adorno, Maria V. Azevedo, 
Maria L. Belloni, Pierre Bourdieu, Manuel Castels, Adilson Citelli, Maria I. Lopes, Edgar Morín e Ismar Soares.

A pesquisa fornece um painel analítico de projetos educomunicativos criados por professores em formação e mapeia ações efetivas desenvolvidas pelas educadoras para controlar problemas políticos e estruturais que dificultam a implementação destes projetos no contexto escolar. Procura ainda traçar um quadro compreensivo das estratégias de legitimação do campo da educomunicação, produzidas pelo grupo de professoras em formação.

O trabalho estabelece como objeto empírico, um estudo de caso que aborda aspectos referentes a um curso denominado Pedagogia da Imagem, organizado pelo Museu da Imagem e do Som da cidade de Campinas - SP. Como resultado, a autora afirma ter observado pouca familiaridade das educadoras com os meios e tecnologias de comunicação. Destaca a existência de um contexto escolar pouco afeito à participação e ao protagonismo de educadores e educandos, portanto pouco favorável à implementação de projetos educomunicativos, havendo necessidade de integrar a comunidade à escola, como estratégia para consolidar esta proposta e deslocar as barreiras geradas pelo sistema escolar. A autora conclui que projetos como esse, podem favorecer a conquista da autonomia do educador, porque the permite atuar em rede articulada, fortalecendo-o na sistematização, defesa e legitimação de projetos educomunicativos.

\section{Educomunicação através do Rádio}

Em 2007, Patrícia Horta Alves apresentou, à Escola de Comunicação e Artes da USP-SP, a tese Educom.Rádio, uma política pública em Educomunicação. A autora propõe analisar a formulação e implementação do Programa Educomunicação pelas Ondas do Rádio - EducomRádio, em escolas públicas do Município de São Paulo entre 2001 e 2004.

A hipótese central do trabalho foi a de que o Programa Educomunicação pelas Ondas do Rádio - Educom.Rádio do NCE/USP, se constitui numa política pública em educomunicação, fruto da relação estabelecida entre o Núcleo de Comunicação e Educação e a Secretaria Municipal de Educação. O objetivo da pesquisa foi mapear e analisar a gênese e o percurso do programa Educom.Rádio, com o intuito de investigar os processos político-administrativos e os conteúdos da política pública que caracterizam as especificidades e complexidades das redes de implementação; as atitudes e os objetivos dos atores políticos; os instrumentos de ação, e os elementos de adaptação das estratégias políticas. Utiliza autores que discutem o campo da educomunicação, como Maria A. Baccega, Manuel Castells, Adilson Citelli, Jorge ljuim, Mário Kaplún, Jesús Martín-Barbero, Brasilina Passareli e Ismar Soares.

A autora, ao concluir seu trabalho, afirma que o projeto Educom.Rádio atende a uma nova concepção de integração universidade-sociedade, como um processo educativo, cultural e 
científico, que aproxima ensino e pesquisa de forma indissociável, viabilizando uma relação transformadora entre estas duas instâncias. Garante que, quanto à esfera de ação do Estado, o projeto contempla as premissas da nova gestão municipal, na qual se distingue nitidamente a centralidade de conceitos como participação, dialogicidade, formação do cidadão e inclusão social, questões fundamentais para o Núcleo de Comunicação e Educação da USP, em suas diretrizes de pesquisa e extensão universitária.

Também em 2007, a dissertação A prática da mediação em processos educomunicativos: 0 caso do Projeto Educom.Rádio, também foi apresentada na Escola de Comunicação e Artes da USP-SP, por Claudia Vicenza Funari.

A pesquisa teve por objetivo traçar o perfil, entender a ação e os conceitos formados por agentes culturais, denominados mediadores, que foram responsáveis pela relação direta entre o Projeto Educom.Rádio e cursistas do projeto, representados por professores, estudantes e demais membros de escolas de Ensino Fundamental da Prefeitura de São Paulo. Buscou ainda identificar o referencial teórico que dá suporte ao conceito de mediação e à prática dos mediadores no projeto Educom.Rádio. Os principais autores citados na pesquisa são Ismar Soares, Adilson Citelli, Lev Vigotsky, Douglas Kellner, José Luiz Illera, Jorge Huergo, José Sacristan, Jesús MartínBarbero e Guillermo Orozco-Goméz, os quais abordam questões ligadas à educação, cultura e a mídia.

A pesquisa procurou também verificar o trabalho que os mediadores desenvolveram, o papel que desempenharam na aplicação do projeto, os obstáculos enfrentados e as vitórias conquistadas na prática cotidiana das capacitações. Buscou igualmente compreender a representação do conceito de mediação e de educomunicação, no imaginário dos mediadores.

O estudo conclui que os princípios educomunicativos foram aplicados na prática, antes mesmo de chegarem às escolas públicas, quando do desenvolvimento do próprio processo de capacitação dos cursistas matriculados no Projeto Educom.Rádio.

Segundo a autora, este projeto caracterizou-se como uma inovação na área educacional, ao trazer, para o mundo da escola, conhecimentos sobre a viabilidade prática dos conceitos educomunicativos. Afirma ter percebido, na figura do mediador, um elemento que atua como facilitador, que abre os caminhos para a recepção ativa, para o diálogo e para a produção, dirimindo os conflitos e negociando as tomadas de decisão, ações fundamentais para a educomunicação.

Ainda em 2007 foi apresentada, à Escola de Comunicação e Artes da USP-SP, a dissertação Educomunicação e expressão comunicativa: a produção radiofônica de crianças e jovens no Projeto Educom.Rádio, de autoria de Renato Tavares Junior. 
A pesquisa investiga a consolidação do campo da educomunicação, com ênfase na área da Mediação Tecnológica na Educação, tendo como objeto produções radiofônicas vinculadas ao Projeto Educom. Rádio, implementado pelo NCE/USP, junto à quatrocentas e cinquenta e cinco escolas da rede municipal de São Paulo, entre 2001 e 2004.

Foram avaliados seiscentos e sessenta e oito programas de rádio e cento e trinta e quatro escolas, atendidas do início ao final do projeto. $\mathrm{O}$ autor afirma ter investigado quantitativa e qualitativamente os programas de rádio realizados por professores e estudantes que participaram do projeto, bem como a continuidade das práticas educomunicativas de produção radiofônica nas escolas, nos dois anos subseqüentes.

A pesquisa busca elucidar em que condições, e com que resultados, as ações educomunicativas podem melhorar os processos comunicativos nas escolas e, ainda, estimular o protagonismo infanto-juvenil, tornando os jovens cidadãos mais críticos e criativos.

Para o autor, a pesquisa contribuiu para analisar a aplicação prática dos conceitos educomunicativos, constatando-se que as escolas pesquisadas, que desenvolvem projetos bem sucedidos, não se pautam pela instrumentalidade tecnológica, mas pela gestão participativa, abertura ao diálogo, busca de melhorias em seus processos comunicativos e pelo estímulo à liberdade de expressão, vinculada à responsabilidade e à ética. Maria Baccega, Maria V. Azevedo, Adiklson Citelli, Jorge Huergo, Mário Kaplún, Jesús Martín-Barbero, Guillermo Orozco-Gomés e Ismar Soares são alguns dos referencias utilizados nessa pesquisa. Ao finalizar seu trabalho, o autor diz esperar que seu trabalho tenha colaborado com as discussões sobre a importância da mediação tecnológica na educação, a fim de proporcionar maior interação do educando com elementos de seu contexto sócio-cultural, transcendendo a mera instrumentalização tecnológica.

No ano de 2008, Renato de Sousa Porto Gilioli defendeu junto ao Programa de PósGraduação em Educação da Faculdade de Educação da USP-SP, a tese Educação e Cultura no Rádio Brasileiro: concepções de rádioescola em Roquete Pinto.

Este trabalho tem por objetivo pesquisar os propósitos educativos e escolares da Rádio Escola Municipal do antigo Distrito Federal (RJ), denominada PRD-5, planejada e dirigida por Edgard Roquete-Pinto. A pesquisa busca também analisar a tentativa mal sucedida de Mario de Andrade, em sua administração frente ao Departamento de Cultura e de Recreação de São Paulo (1935-1938), de organizar uma rádio escola que até chegou a ser criada, mas que, no entanto, não teve continuidade.

O autor procurou estabelecer contrapontos entre as duas experiências de rádiodifusão educativas, buscando compreender aspectos essenciais da estruturação e desenvolvimento dos primeiros projetos neste sentido, no Brasil. Enfoca a inserção da radiodifusão entre as tecnologias educacionais e a constituição do campo educativo-cultural, em contraposição ao comercial. Aborda as mudanças ideológicas de Roquete-Pinto, de uma concepção de rádio-cultura para a de 
rádio-educação, consolidado na constituição da emissora PRD-5, observando seu contexto no âmbito da radiodifusão escolar e as práticas da emissora, com atenção para as metodologias e os conteúdos utilizados. Além disso, analisa as disputas político-institucionais nas quais a PRD-5 estava envolvida e alguns desdobramentos históricos decorrentes deste período. Para abordar essas questões, o pesquisador apoiou-se em autores como Mário de Andrade, Pierre Bourdieu, Paulo Freyre, Ana Mendonça, Edgard Roquete-Pinto e Anísio Teixeira.

O autor afirma haver necessidade de se ampliar o debate sobre a educação a distância no Brasil, de modo que a não restringi-la a uma mera questão de forma ou de inovação tecnológica, mas que se discuta suas potencialidades, bem como os limites impostos pela não presencialidade na educação. Conclui afirmando que, caso as tecnologias continuem sendo vistas como uma solução isolada e inequívoca para resolver problemas que remetem a processos culturais mais amplos, dentre os quais a transmissão de saberes e a função social da escola, o debate corre o risco de se tornar empobrecido.

Em 2009, a dissertação Programa Educom.rádio: um estudo sobre representações, foi apresentada ao Programa de Pós-Graduação em Educação da USP, por Francine Sayuri Segawa.

Este trabalho buscou realizar um levantamento e a análise das representações sobre educação, num grupo de agentes que atuou no Programa Educom.Rádio, realizado pelo NCE/USP, em parceria com a Secretaria de Educação de São Paulo, entre 2001 e 2004. A proposta deste programa, segundo a autora, era promover a reflexão sobre o uso dos meios de comunicação na escola, através de um curso no qual eram oferecidas atividades práticas e teóricas relacionadas ao conceito de educomunicação, além de laboratórios de produção radiofônica. As representações foram estudadas em relatórios produzidos pelos integrantes de uma equipe que atuava em escolas municipais, durante o ano de 2004. O trabalho realiza um estudo sobre o uso do rádio na educação brasileira, a formulação e a estrutura do Programa Educom.Rádio e a tentativa da fundação da área da educomunicação, como campo de conhecimento. Para dar sustentação e fundamentar a pesquisa, o autora diz ter sido importante aprofundar estudos sobre a constituição do programa Educom.Rádio e sobre o conceito e linguagem da educomunicação, questões centrais para a compreensão da proposta pedagógica do curso. Utiliza autores como Pierre Bourdieu, Roger Chartier, Bernard Charlot, Ismar Soares e Adilson Citelli, além de boletins informativos do Núcleo de Comunicação e Educação da ECA/USP.

A pesquisa concluiu que os relatórios serviram como espaço de monitoramento e avaliação das atividades dos cursistas e das condições materiais do curso, de acordo com critérios de classificação que foram estabelecidos pela própria equipe no decorrer da prática pedagógica, em consonância com o referencial teórico do projeto. 
Também em 2009, Mauro Soares Cordeiro apresentou a dissertação Política Educacional, elaboração e continuidade: o programa Educom.rádio nas escolas municipais da capital de São Paulo, ao Programa de Pós-Graduação em Educação da Faculdade de Educação da USP-SP.

O trabalho examinou o Programa Educom.Rádio, buscando construir uma análise dos processos de decisão na elaboração e continuidade de programas de educação escolar pública, procurando compreender se a forma de elaboração de programas dessa natureza tem influência sobre sua continuidade.

Para tal finalidade, foram realizadas entrevistas com pessoas que participaram da tomada de decisão sobre os mesmos, as quais eram ligadas de alguma forma ao NCE/USP, sendo localizadas através de documentos oficiais produzidos sobre o programa Educom.Rádio. Os depoimentos, segundo o autor, serviram para balizar as diretrizes e critérios envolvidos nas decisões que levaram à adoção deste programa e sua continuidade. Entre os autores que deram sustentação teórica para a pesquisa, destacam-se Roberto Andrade, Elie Ghanem, Marcos Lima e Antonio Viana. O autor conclui que as decisões fundamentais concernentes ao programa Educom.Rádio, tanto para sua elaboração quanto para sua continuidade, foram tomadas por diretrizes e critérios de um pequeno grupo de pessoas, todas situadas no nível superior da administração educacional do município. Entende-se, assim, que a participação de um grande número de agentes não se constituiu em fator preponderante para continuidade deste projeto.

\section{Utilização de Recursos Vídeo-tecnológicos e Televisivos na Educação}

No ano de 2005, Rosimar Ramos da Mota apresentou a dissertação O uso pedagógico das tecnologias de vídeo e televisão: análise do Programa TV Escola no município de Tubarão - SC, ao Programa de Pós-Graduação em Educação e Cultura da UDESC-SC.

Neste trabalho discutem-se as possibilidades oriundas dos atuais artefatos tecnológicos e suas implicações na educação, apontando para a necessidade de se refletir sobre o uso pedagógico dos meios de comunicação, com ênfase para o vídeo e televisão. Neste sentido foi analisada a implementação do Programa TV Escola no município de Tubarão-SC e sua contribuição para o uso pedagógico do vídeo e da televisão nas escolas públicas estaduais. A investigação analisa a formação de professores, proposta pelo programa TV Escola, bem como os limites e possibilidades da efetivação dos objetivos propostos, a partir da realidade das escolas publicas estaduais sediadas no município. Foram confrontados os discursos dos órgãos oficiais, responsáveis pelo Programa, com o processo vivenciado nas escolas pelos professores e gestores de cinco escolas da rede pública estadual.

A autora informa que o Programa TV Escola se caracteriza como um conjunto de ações televisivas destinado à capacitação docente e ao acesso dos alunos às novas tecnologias de R. B. E. C. T., vol 4, núm 2, mai./ago. 2011 
informação e comunicação. Transmitido para todo o país, em circuito fechado de televisão, o programa foi criado pelo Ministério da Educação para o aperfeiçoamento e valorização dos professores da rede pública de ensino. A autora entrevistou e aplicou questionários entre professores e gestores de cinco escolas da rede pública estadual de ensino. Também analisou documentos, entre eles os relatórios do Projeto TV Escola (1996-2000) e relatórios divulgados pela Universidade do Extremo Sul Catarinense, sobre a realização do Programa TV Escola, além de materiais impressos e audio-visuais divulgados pelo Programa.

A pesquisa apontou que recursos tecnológicos, quando integrados ao ensino, são utilizados basicamente como um recurso técnico. A competência do professor para utilizar pedagogicamente as tecnologias de vídeo e televisão necessitaria ser priorizada, através de sua formação inicial ou por políticas de formação continuada. A autora fundamentou sua investigação em diversos autores, destacando-se Maria Luiza Belloni, Lucídio Bianchetti, Adilson Citelli, Joan Ferrés e Paulo Freire.

Também em 2005, Bruno Jorge de Sousa apresentou ao Programa de Pós-Graduação em Educação da Universidade Católica de Goiás (GO), a dissertação $O$ cinema na escola: aspectos pedagógicos do texto cinematográfico. $\mathrm{O}$ trabalho tem como objeto de estudo o uso do cinema na escola, delimitando seus aspectos ideológicos e pedagógicos, observados no processo de seleção de filmes e sua utilização na educação formal.

A pesquisa serviu-se da concepção de que a experiência cinematográfica possui a potencialidade para educar o homem. A revisão da literatura oferece perspectivas para que se compreenda o cinema como um agente educativo, por se tratar de uma produção cultural significada, portadora de um discurso ideológico, que se vale de estratégias de comunicação específicas para expor conteúdos. A concepção de cinema como meio pedagógico e ideológico apóia-se no debate contemporâneo sobre as capacidades educativas dos meios de comunicação. À escola caberiam ações para promover a formação de um estudante capaz de ler, interpretar e analisar criticamente as mídias e as novas tecnologias da comunicação. Esta reflexão indica a necessidade de se conhecer de que forma a escola vem utilizando o cinema em suas práticas educativas.

A pesquisa, de natureza qualitativa, se deu em três etapas distintas: pesquisa bibliográfica, pesquisa de campo (realizada em quatro escolas de Ensino Médio, na cidade de Goiânia-GO) e análise do referencial teórico. Entre os autores de suporte, destacam-se Maria Luiza Belloni, Sergei Eisenstein, Jesús Martín-Barbero, Henry Giroux e Margarida Kunsch.

Em suas conclusões, o autor argumenta que uma reflexão sobre cinema e educação necessita de uma maior aproximação entre estes dois campos. Afirma que a justificativa para a 
presença do texto cinematográfico na escola vem sendo somente seu uso para finalidades pedagógicas, desta forma negligenciando-se sua condição de texto ideológico. Mesmo entendendo que algo de lúdico compõe a circunstância do uso do cinema no ambiente escolar, defende que a intenção de produção de saberes deveria ser o princípio a nortear esta prática.

Em 2006, a dissertação Televisão em solo educativo: educando o olhar, foi apresentada ao Programa de Pós-Graduação em Educação da Universidade Federal do Rio Grande do Norte (RN), por Sandro da Silva Cordeiro.

A pesquisa apresenta uma reflexão acerca da televisão no cotidiano infantil. Aponta para a necessidade da incorporação dos meios de comunicação e informação nas propostas educativas, de maneira a promover a aproximação das duas áreas pela imbricação de suas respectivas epistemologias. Descreve uma pesquisa de campo, realizada em escolas públicas e privadas de educação infantil de Natal-RN, mostrando em qual perspectiva os professores utilizam as linguagens nesta etapa da escolarização, priorizando os elementos televisuais. Faz uso de entrevistas com professores e orientadores educacionais de escolas públicas e privadas, bem como de análise documental, trazendo para discussão a Lei de Diretrizes e Bases da Educação e o Referencial Curricular Nacional para a Educação Infantil. Procura identificar, nesses documentos, a existência de preocupações com o emprego das tecnologias e das mídias na educação. $O$ autor referencia seu trabalho com leituras que discutem a influência da televisão nos processos de ensino, destacando-se as de Marco de Andrade, Maria Luiza Belloni, Joan Ferrés e Jesús MartínBarbero.

Cordeiro conclui seu trabalho apontando que há evidências de precariedades na formação dos educadores, quanto à existência de conhecimentos acerca da linguagem das mídias. Ressalta ter verificado um desconhecimento dos educadores, sobre o uso das novas tecnologias de informação e de comunicação. Esta constatação permite concluir que os professores encaram os aparatos tecnológicos como meros recursos pedagógicos, ou simplesmente como elementos que podem servir para o entretenimento e ocupação dos alunos, nos horários vagos.

No ano de 2008, Helenita Sommerhalder-Miike defendeu a dissertação Oficina de TV, uma prática educomunicativa: estudo de caso de uma criança abrigada, junto à Faculdade de Filosofia, Ciências e Letras da USP-SP.

Para a autora, de um lado está a educomunicação, um campo novo, surgido da interface entre a educação e a comunicação; de outro, crianças que vivem em abrigos, entidades comumente vistas como lugares de exclusão.

O trabalho busca compreender as possibilidades de ganhos que a participação em uma oficina de TV pode trazer para crianças abrigadas. Procura identificar mudanças na condição de desenvolvimento destas crianças, expressas em seus contextos de vida, que poderiam ser consideradas como decorrentes de sua participação no projeto. 
A pesquisadora utiliza-se de registros em arquivos, entrevistas, observação direta, observação participante e de artefatos físicos. Referencia sua pesquisa utilizando autores como Pierre Bourdieu, David Buckinghan, Adilson Citelli, Joan Ferrés, Paulo Freire, Jesús Martín-Barbero e Ismar Soares.

Esclarece que foram realizadas oficinas onde se fez uso da estratégia "aprender fazendo" e que nestas, foi possível utilizar a câmera de vídeo como uma ferramenta de educação para a mídia. Entende que, como a educomunicação é uma proposta ainda recente e pouco estudada, sua pesquisa teve caráter exploratório, sendo necessário contemplar uma diversidade de outros dados, evitando-se dessa forma resultados insatisfatórios ou superficiais.

Ao concluir seu trabalho, a autora afirma que o desenvolvimento do projeto permitiu visualizar o uso da câmera de vídeo, na educação para a mídia, como um dispositivo de educação e de desenvolvimento, capaz de potencializar a experiência de vida de crianças, ao quebrar a relação mítica com o objeto TV e auxiliar na percepção de recursos próprios, especialmente para aquelas que ainda não dominam a leitura e a escrita.

\section{Utilização da Internet em Processos Educativos}

Em 2006, Neiva Beatriz Marinho Pinel defendeu, junto ao Programa de Pós-Graduação em Educação da Pontifícia Universidade Católica do Paraná (PR), a dissertação Educação, internet e suas interações com o sujeito: o desafio do contexto escolar.

O trabalho tem como objetivo identificar os usos que professores e alunos fazem da internet, dentro e fora do contexto escolar, verificando se ocorrem interferências na relação pedagógica que se estabelece entre estes dois grupos, pela aproximação com o uso das tecnologias de comunicação e informação. Analisa ainda as intenções que levam alunos e professores a utilizarem esta tecnologia, bem como caracterizar os seus diferentes usos. Identifica as preferências dos alunos e dos professores em relação à internet, bem como avalia as áreas de intersecção entre estas preferências.

A pesquisa foi realizada com setenta e seis alunos e vinte e dois professores da primeira série do Ensino Médio, em duas escolas da rede particular de ensino da cidade de Curitiba-PR. Utilizou um referencial teórico que discute a interface entre educação e comunicação, destacando-se os autores Maria Luiza Belloni, José Moran, José Sacristan, Manuel Castells, Bernard Charlot, Adilson Citelli e Ismar Soares.

A autora, ao concluir seu estudo, afirma que nestas escolas, apesar da grande quantidade de aparatos tecnológicos de informação disponibilizados aos alunos, a internet não está sendo 
usada como possibilidade pedagógica. Para ela, a escola ainda não se encontra preparada para romper totalmente com o modelo tradicional de ensino. Os professores não conseguem inovar sua forma de ação e, consequentemente, deixam de contribuir para superar o modelo dominante. Ressalta a existência de indícios de que alguns professores parecem inseguros para "transgredir" sua prática, apesar de reconhecerem a necessidade de mudanças nesse sentido. Finaliza apontando para a necessidade de atualização dos professores, para o uso das novas tecnologias de informação e comunicação.

Em 2007, foi apresentada ao Programa de Pós-Graduação em Educação da Universidade do Oeste Paulista - UNOESTE-SP, por Carlos Eduardo Duarte Peinado, a dissertação A internet na construção do conhecimento: a importância das mediações.

O trabalho tem por objetivo contribuir para o aperfeiçoamento de procedimentos de ensino/aprendizagem dentro do conceito de comunicação do educador Paulo Freire, além de analisar a inserção da internet, como ferramenta de estudos e pesquisas acadêmicas, no cotidiano de estudantes de um curso de administração de empresas, de uma instituição particular de ensino de Maringá-PR,

O autor procura verificar as características da relação professor-aluno, quando mediatizados pela Internet, considerando que este meio, nos últimos anos, ganhou representatividade acadêmica enquanto fonte de informação e interatividade, tornando-se extremamente importante sua discussão no processo de desenvolvimento, tanto de alunos quanto de professores. Parte da análise da comunicação como "campo do conhecimento", abordando questões como a educação para os meios, a educação através dos meios, a relação entre a mídia e o sujeito internauta, a relação entre ensino, pesquisa e informação, e a utilização de recursos didáticos pedagógicos na construção do conhecimento.

A pesquisa utiliza autores que transitam entre os campos da educação e da comunicação, destacando-se Maria A. Baccega, Manuel Castells, Adilson Citelli, Paulo Freire, Jesús OrozcoGoméz e Ismar Soares.

Para o autor, os resultados expressam preocupações com a forma pela qual a internet e seus conteúdos vem sendo utilizados pelos alunos, além da maneira pela qual organizam seus trabalhos. Para ele, o uso da internet, enquanto meio comunicacional, possibilita pensar em novas formas de aprendizagens colaborativas, para o processo de formação continuada de professores, na reflexão sobre o uso da informática educativa, na comunicação integrada por rede e em projetos político-pedagógicos adaptados a essa nova realidade.

Ao concluir seu estudo, o autor afirma ter certeza de que a internet, como ferramenta de comunicação, de experimentação e de ampliação do diálogo, pode propiciar uma nova vivência, ao se constituir como um instrumento de inter-relação entre os mundos virtual e real. 
Em 2008, Maria Izabel de Araujo Leão apresentou, ao Programa de Pós-Graduação em Ciências da Comunicação da USP, a dissertação $O$ papel da Internet nos Projetos Educomunicativos do NCE/USP.

Nesta pesquisa, a autora investiga o papel exercido pela internet nos projetos educomunicacionais implementados pelo NCE/USP, buscando compreender como este vem se apropriando da linguagem virtual, nos diferentes programas implantados a partir de $2001 \mathrm{em}$ redes públicas de educação, além de identificar a especificidade do emprego da linguagem digital, tanto no âmbito da formação presencial quanto no da formação à distância. Utiliza como amostragem os sites dos projetos Educom.TV, TodeOlho.TV, Educom.Rádio e Educom.Radio.centro-oeste, do NCE/USP.

A pesquisa faz um levantamento dos fundamentos da educomunicação que sustentam as ações do NCE e sua decisão de construir sete sites, num total de nove experiências em linguagem virtual, elaborados durante os doze anos de atividade do núcleo.

Para as reflexões sobre educomunicação, a autora faz uso dos textos de Ismar de Oliveira Soares. Para construir os referenciais que possibilitaram a análise da presença da internet e do mundo virtual na sociedade contemporânea, utilizou uma ampla literatura, destacando-se as obras de Maria A. Baccega, Manuel Castels, Adilson Citelli, Brasilina Passarelli, Guillermo OrozcoGomés e, novamente, Ismar Soares.

A autora afirma, nas suas conclusões, acreditar que os projetos analisados tenham contribuído para visualizar um caminho a ser trilhado pela educomunicação, contudo, admite que eles ainda se encontram restritos à academia, não fazendo parte do imaginário da escola pública. Segundo ela, a internet para o NCE, precisa ser melhor lapidada, de forma a colaborar com o processo de educomunicação. Argumenta que este núcleo necessita se apropriar desta ferramenta, como uma ação na constituição desse processo, e não apenas como veículo de comunicação.

Em 2009, Rafael Gué Martini defendeu a dissertação Educação e Comunicação em Ambiente Associativo: Web Site como um dispositivo de educomunicação, junto ao Programa de Pós-Graduação em Educação da UDESC-SC. Realizou um estudo de caso, qualitativo, cujo objetivo foi o de compreender as relações entre educação e comunicação, presentes no processo de construção de um web site de uma associação comunitária. O problema de pesquisa dizia respeito à viabilidade de um web site ser identificado como um dispositivo de educomunicação. Neste sentido, o autor buscou compreender a organização do projeto deste web site, bem como analisar o desenvolvimento de estratégias de educomunicação inerentes ao mesmo. O referencial teórico 
foi o da Teoria Dialógica de Paulo Freire, aliado às experiências de comunicação popular, de Mario Kaplun, e aos estudos sobre educomunicação, de Ismar de Oliveira Soares.

O autor dessa dissertação entende que não basta conhecer, ou se estar familiarizado, com a tecnologia, para que se consiga fazer a passagem da comunicação para a educação. Afirma que, se isto é uma tarefa difícil para professores, é ainda mais desafiador para pessoas que não tem como proposta ensinar algo. No entanto, esta relação precisa ser efetuada, não apenas na sala de aula, mas em qualquer processo de aprendizagem. Defende a importância do fortalecimento de um "ecossistema comunicacional" na associação pesquisada, como forma de ampliar a socialização de conhecimentos em seus domínios, além de permitir que as pessoas que dela fazem parte, também encontrem novos caminhos que as conduzam à criação de um ambiente mais equilibrado e sustentável.

\section{Meio Ambiente e Mídia}

Em 2005, Fabiana Mauro apresentou a dissertação Mensagens sobre a natureza: um estudo de duas revistas de turismo, ao Programa de Mestrado em Ecologia de Agroecossistemas da USPSP. Sua pesquisa objetiva construir uma análise sobre as mensagens veiculadas por duas revistas de turismo brasileiras, tendo como exemplo as representações midiáticas sobre o Parque Nacional da Chapada Diamantina. Procura quantificar o espaço destinado às mensagens envolvendo questões ambientais e ao turismo de natureza, e descrever como essas são construídas e expostas ao grande público, utilizando materiais divulgados entre os anos de 2001 e 2002.

A escolha deste parque, como tema de análise, se deu em função do mesmo se constituir num dos locais do Brasil que melhor representa o turismo voltado à contemplação e ao contato com a natureza. Esta análise fundamenta-se através de pesquisa quantitativa, envolvendo uma medição do espaço dedicado por esses veículos ao tema, levando em conta o valor que isto representa financeiramente para a revista, além de pesquisa qualitativa, a qual analisa as mensagens, procurando traduzir seu sentido e sua articulação. A autora faz ainda um balanço sobre a influência que os meios de comunicação exercem sobre a sociedade e a possibilidade de que temas ambientais sejam constantemente trazidos à tona, possibilitando uma maior reflexão sobre suas causas e seus efeitos.

A autora utilizou, entre outros autores, Pierre Bourdieu, Joan Ferrés, Enrique Leef e Marshal McLuhan, como referenciais teóricos de sua pesquisa. Segundo ela, nos veículos analisados, o tema meio ambiente é visto apenas como um valor econômico, ocorrendo banalização dos conceitos técnicos e científicos relacionados a esta área. Afirma que os mesmos tentam persuadir os leitores através de técnicas de linguagem, procurando influenciá-los para a compra de pacotes turísticos com destinos de natureza exuberante. Constata que as reportagens 
não são suficientes para esclarecer e conscientizar os leitores sobre os problemas advindos da prática do turismo de natureza, e que as mensagens pecam ao não enfocar a existência de problemas sociais, econômicos, políticos e ambientais nos locais veiculados.

Ainda em 2005, Lúcia de Fátima Estevinho Guido defendeu a tese Educação, televisão e natureza: uma análise do Repórter Eco, apresentada ao Programa de Pós-Graduação em Educação da Universidade de Campinas - UNICAMP-SP.

Esta pesquisa dedica-se ao estudo das questões ambientais tais como são tratadas na televisão. O Programa Repórter Eco foi escolhido como elemento de análise, por ser veiculado por uma emissora pública e educativa, por trazer reportagens sobre o Brasil, e, num primeiro olhar, por conceder um tratamento menos espetacular e superficial às questões ambientais. Surgido em 1992, na TV Cultura (SP), o programa tem como objetivo discutir questões ambientais e inseri-las no cotidiano das pessoas.

O trabalho analisa a forma adotada pela televisão para discutir a questão ambiental, tendo em vista que diversas pesquisas apontam este veículo como o principal meio de divulgação de informações ambientais para alunos e professores.

Para a autora, um dos principais propósitos do trabalho é fazer uma reflexão sobre as contradições e reiterações presentes no embate entre diferentes vozes, sons e imagens presentes na televisão, em especial no programa analisado. Esclarece que a opção por este programa permitiu aprofundar o tratamento de aspectos candentes da discussão ambiental contemporânea, no interior de uma unidade audiovisual de comunicação de massa dedicada especificamente a esta complexa temática.

Procura realizar uma análise geral do programa, sendo selecionadas as reportagens sobre as quais o trabalho deteve-se de forma particular. Seus aspectos educativos mereceram atenção constante, revelando que a educação ambiental vem sendo tratada de maneira prescritiva, sem aprofundar os impasses do discurso ecológico.

A autora não faz conclusões generalistas sobre o assunto pesquisado; ao contrário, procura construir uma análise particularizada dos temas discutidos nos programas que compuseram este estudo de caso. Maria A. Baccega, Cristina Bruzzo, Marília Franco e Wencesláo Oliveira Junior, são alguns dos autores que compõem o referencial teórico da pesquisa.

Em 2006, a dissertação Imprensa e meio ambiente: as mudanças na cobertura jornalística entre a Rio-92 e a Rio+10 - o caso da Gazeta Mercantil foi apresentada por Denise Juliani de Arruda ao Programa de Pós-Graduação em Educação da Escola de Comunicação e Artes da USPSP. 
O trabalho analisa mudanças na cobertura jornalística de temas ambientais no período compreendido entre a Rio 92 e a Rio +10 , a partir da produção do jornal Gazeta Mercantil. Objetiva ainda identificar as mudanças ocorridas, neste jornal, na cobertura de temas ambientais, procurando responder a seguinte questão: como um veículo voltado para o meio empresarial tratou o tema meio ambiente a partir da Conferência Rio 92?

A autora aborda a relação entre imprensa, suas fontes, meio ambiente e economia, tendo como foco a contribuição da atividade das empresas no processo de degradação do planeta. Traça um pequeno histórico do movimento ambientalista no Brasil e no mundo, além de expor uma análise da cobertura de temas ambientais pela imprensa brasileira.

Paralelamente à análise destas matérias, realiza uma pesquisa com jornalistas dos principais jornais de São Paulo, buscando enriquecer e melhor compreender o tema e os resultados obtidos na avaliação dos conteúdos pesquisados na Gazeta Mercantil. Para dar maior sustentação à pesquisa, a autora lançou mão de autores como Victor Baccheta, Samyra Crespo, Pedro Leitão, Edgar Morín e Wencesláo Oliveira Junior.

Os resultados da pesquisa permitem afirmar que, entre as duas conferências das Nações Unidas, ocorreram mudanças na cobertura do tema ambiental, por parte do jornal que foi objeto da pesquisa. Entre as conclusões da autora, destacam-se: a constatação de uma queda no volume de matérias sobre meio ambiente, entre 1992 e 2002; uma mudança de foco, com redução de matérias envolvendo denúncias, e a ampliação de notícias sobre investimentos e negócios na área ambiental.

O estudo também aponta para uma mudança na distribuição das fontes consultadas. Segundo a autora, embora as fontes governamentais tenham mantido predominância sobre as demais, no período analisado, cresceu a participação de outras fontes como a sociedade civil, empresas e especialistas na área ambiental.

No ano de 2007, Ana Paula Luckman apresentou uma dissertação ao Programa de PósGraduação em Educação da UFSC-SC, tendo por tema Educação, jornalismo e meio ambiente: leituras sobre a crise ecológica no contexto do aquecimento global. A pesquisa busca estabelecer relações entre jornalismo, educação e meio ambiente, investigando, através de estudos de recepção, possíveis aspectos educativos dos noticiários sobre a crise ambiental, veiculados pelos meios de comunicação.

O trabalho objetiva fazer uma reflexão sobre as responsabilidades do público leitor/espectador, sobre o que é veiculado nos meios de comunicação de massa e de que forma esse mesmo público pode aprender a direcionar outros olhares, sobre suas produções.

Analisa trabalhos acadêmicos que apresentam críticas ao jornalismo ambiental, desenvolvendo estudo empírico, objetivando verificar como as notícias sobre meio ambiente são 
recebidas pelo público. Utiliza, como sujeitos de pesquisa, uma amostra de estudantes da Universidade Federal de Santa Catarina.

A autora afirma que procurou estabelecer relações entre jornalismo, educação, consciência e conhecimento, a partir de discussões sobre textos de jornais e de revistas, que abordam a temática do aquecimento global. Utilizou-se de um amplo referencial teórico, destacando-se, entre os autores consultados: Maria A. Baccega, Victor Baccheta, Maria Luiza Belloni, Genebaldo Dias, Paulo Freire, Jesús Martín-Barbero, Régis de Morais, Edgar Morín e Guillermo OrozcoGómez.

Luckman considera que o jornalismo consegue cumprir uma função educativa, embora, em grande parte dos casos, represente o meio ambiente através de visões estreitas, sensacionalistas ou superficiais, como constatam os estudos apresentados. Entende que a própria atividade de leitura crítica pode se constituir numa maneira de superar as limitações do jornalismo, e, para tal finalidade, recomenda a inserção de aspectos da mídia-educação na formação de jovens.

Em 2008, a dissertação A visão da ecologia no Jornal Nacional foi apresentada por Roberto Lestinge ao Programa de Mestrado em Ecologia Aplicada da USP-SP. O autor analisa a linguagem jornalística utilizada pelo Jornal Nacional, da Rede Globo de Televisão, em relação aos temas ambiente e ecologia.

A pesquisa objetiva desvendar as estratégias de produção de sentido do telejornal, verificando como este soluciona a transversalidade dos temas pesquisados, considerando que existe uma multiplicidade de fatores importantes, nem sempre revelados na notícia. Quantifica o tempo dedicado às matérias sobre ecologia e ambiente no Jornal Nacional, estabelecendo relação percentual com o tempo total do programa. O autor afirma ter observado a formação de diretrizes que apontam para a preponderância de determinados temas, como biocombustíveis e aquecimento global. A partir da leitura das reportagens sobre esses assuntos, o trabalho busca compreender se estas oferecem integridade em sua apresentação, ou optam por uma abordagem superficial. Como referenciais bibliográficos, a pesquisa utilizou, entre outros autores, Maria A. Baccega, Pierre Bourdieu, Adilson Citelli, Marcondes Filho, Jesús Martín-Barbero e Muniz Sodré.

O autor conclui que o programa analisado possui uma postura governista, ao adotar em sua agenda a promoção de programas nacionalistas. Aponta também que o Jornal Nacional utiliza uma linguagem alarmista, quando apresenta relatórios ambientais, banalizando a natureza e demonstrado-a como um espetáculo. Não explora a fundo as correlações de poder, quando ignora a cadeia de interesses envolvida, por exemplo, na produção dos biocombustíveis, nos desmatamentos e nas pressões do agronegócio, entre outros temas. Fala de educação ambiental utilizando exemplos de pouco impactos, ignorando questões mais relevantes. Omite temas 
controversos. Não estabelece relações entre o consumismo e suas conseqüências ao ambiente, retirando do espectador o poder de agir conscientemente. Ao não apresentar as causas externas das notícias, o autor conclui que o jornal nega a coerência interna da reportagem, pois não existe fato sem origem ou sem conseqüências.

\section{Ciência e Tecnologia na Mídia}

Em 2005, a dissertação $O$ ensino de CTS através de revistas de divulgação científica foi defendida por Marcio José da Silva junto ao Programa de Pós-Graduação em Educação Científica e Tecnológica da UFSC-SC.

O autor procurou construir um instrumento de análise capaz de identificar aspectos presentes em artigos de divulgação científica, relevantes para uma educação CTS no ensino médio, sendo subsidiada por referenciais legais e teóricos. Quanto aos primeiros, foram analisadas as determinações e recomendações constantes em documentos oficiais (Constituição Federal, LDB, DCNEM, PCNs) e, na segunda parte, foram articulados fundamentos teóricos de enfoque CTS e da Divulgação Científica, sendo consultados autores como Jose Acevedo, José Peres Angotti, Décio Auler, Walter Bazzo, Paulo Freire, José López e Jose Solomon.

Segundo o autor, a pesquisa aponta para a necessidade da construção de um instrumento capaz de auxiliar a realização da análise de artigos, presentes em revistas de Divulgação Científica, para o ensino de CTS. Desta forma, o professor poderá identificar elementos a serem abordados durante o desenvolvimento de estratégias didáticas. As diversas considerações apresentadas ao longo do trabalho revelam que apenas a identificação dos elementos contemplados no artigo não é suficiente para que se possa realizar este desenvolvimento. Para o autor, a utilização do instrumento de análise deve articular-se com a organização inicial da estratégia e com os diversos procedimentos utilizados durante o processo de ensino e aprendizagem.

Ainda junto ao Programa de Pós-Graduação em Educação Científica e Tecnológica da UFSCSC, no ano de 2006, Mariana Brasil Ramos apresentou a dissertação Discurso Sobre Ciência e Tecnologia no Jornal Nacional.

A autora, considerando que a televisão tornou-se fonte importante de divulgação científica e tecnológica, empreendeu uma análise dos discursos sobre ciência, no telejornal de maior audiência no Brasil, o Jornal Nacional. Buscou verificar como programa televisivo produz sentidos sobre ciência, através da análise das condições de produção dos discursos, vinculada à analise das reportagens.

O trabalho investiga o fazer telejornalístico, através de leitura de artigos da área, conversas com profissionais do ramo, publicações sobre o Jornal, sobre divulgação científica e outros textos, que contribuíram para a constituição de um panorama de como este telejornal produz seus 
discursos sobre ciência e tecnologia. Autores como Azevedo, Walter Bazzo, Irlan V. Linsingen, Luiz Pereira, Maria Luiza Belloni, Pierre Bourdieu, Luiz Rebello e Paulo Freire, compõem o referencial teórico desta dissertação.

A pesquisa analisa temas sobre genética e biotecnologia, de onde emergem visões essencialmente utilitaristas da ciência e da tecnologia, vinculadas a um modelo linear de desenvolvimento. Os conceitos científicos exprimem sua utilidade imediata e estas explicações, muitas vezes, são construídas de forma muito similar às escolares, porém, justificando a necessidade de sua aprovação e adesão públicas. Apesar de verificar um esforço para a espetacularização e polemização, a autora afirma ter percebido que as reportagens acabam justificando as pesquisas científicas, pouco expondo as implicações éticas e morais que possam levar o público a questionar seus avanços. Ao mesmo tempo, verifica a ocultação dos jogos políticos e das relações de poder, valendo-se de uma espetacularização da Ciência e da Tecnologia. Aponta ainda para a escola como espaço de possível debate dos discursos midiáticos, com a intenção de problematizar as questões científicas e tecnológicas, ampliando assim as possibilidades discursivas, além das construídas pela mídia.

Também em 2006, junto ao Programa de Pós-Graduação da PUC-PR foi apresentada a dissertação Educação para a Divulgação Científica: o professor-pesquisador e a relação comunicação, ciência e sociedade, por Juliane Martins. A pesquisa investiga a visão do professorpesquisador sobre a divulgação científica, como um protagonista da relação entre ciência e sociedade.

Utilizando autores como Marilda Behrens, Manuel Calvo Hernando, Herbert Marcuse, Luiza Massarani e Arthur Meadows, a autora parte da compreensão de que o professor- pesquisador não deve ficar restrito à universidade. Para ela, sua responsabilidade diante da sociedade é a de levar o conhecimento, produzido nas instituições, à comunidade. Aponta os meios de comunicação como possíveis mediadores entre pesquisadores e público, por meio da divulgação científica, como uma maneira de aproximar ciência e público.

Para investigar a visão do professor-pesquisador sobre divulgação científica, a autora utilizou uma metodologia quantitativa, de caráter exploratório, e outra qualitativa. Ambas tiveram como alvo o aprofundamento de aspectos subjetivos da pesquisa, colhendo dados junto a professores-pesquisadores de programas de pós-graduação, de duas universidades de CuritibaPR.

Os resultados dessa investigação apontam para a necessidade de um maior entendimento recíproco entre ciência e mídia. Tanto os meios de comunicação deveriam investir mais na 
divulgação de temas científicos, quanto os pesquisadores na divulgação de seus conhecimentos à sociedade, utilizando-se dos meios de comunicação social.

No ano de 2007, o tema Divulgação científica e educomunicação, foi objeto de dissertação apresentada por Amanda Souza de Miranda, ao Programa de Pós-Graduação em Educação Científica e Tecnológica da UFSC-SC.

A pesquisa procura demonstrar a existência de conexões entre três campos de conhecimento: educomunicação, divulgação científica e alfabetização científica.

A autora parte do princípio de que a alfabetização científica deve contemplar a vida dos estudantes fora da sala de aula, inclusive a forma como estes consomem os produtos midiáticos. Afirma que, para que isto ocorra, é necessário que os professores estejam atentos ao jornalismo científico, que segundo ela, integra o cotidiano de jovens em formação. Salienta que uma das possibilidades dessa alfabetização científica pode ser direcionada por princípios da educomunicação. Para tal finalidade, propõe a elaboração de um jornal escolar que trabalhe textos de divulgação científica, visando promover a alfabetização científica e midiática dos estudantes.

A autora entende que educar com um jornal de ciências, elaborado pelos estudantes e produzido na própria escola, seria uma oportunidade de thes oferecer a possibilidade de compreenderem a mídia e a forma como esta trata a ciência. Seria também uma forma de abrir o diálogo na escola e torná-los protagonistas e produtores de informação.

A autora lança mão de autores relacionados aos campos da educação, da educomunicação e de CTS, destacando-se Décio Auler, Demétrio Delizoicov, Adilson Citelli, Paulo Freire, Jorge ljuim, Jesús Martín-Barbero, Luiza Massarani, Guillermo Orozco-Gómez e Ismar Soares.

Realizou um estudo empírico, que se fundamenta na construção de um jornal escolar de ciências. Relata as dificuldades em envolver um grande número de alunos na elaboração de um jornal escolar. Para ela a prática educomunicativa, para ter êxito, depende da participação e do nível de envolvimento de seus atores, devendo se constituir em uma prioridade dentro da escola, tal como o ensino dos conteúdos acadêmicos.

\section{Educação nos Meios de Comunicação}

Em 2007, Marcos Luiz Cripa elaborou o trabalho denominado A cobertura da educação no Jornal Folha de São Paulo: uma análise comparativa dos anos 1973 e 2002, apresentado ao Programa de Pós-Graduação da Escola de Comunicação e Artes da USP-SP.

A dissertação analisa o comportamento adotado pelo Jornal Folha de São Paulo sobre a cobertura do tema Educação, em dois períodos distintos, 1973 e 2002. O ano de 1973 corresponde à implantação de uma editoria específica para cobertura da área da educação. Já no 
ano de 2002, as matérias relacionadas a este tema passaram a fazer parte de um caderno não específico, denominado Cotidiano, tal como existe ainda hoje nesse jornal.

O autor analisa o conteúdo de 61 edições do veículo pesquisado, divididas entre os dois períodos estudados, e realiza entrevistas com jornalistas e direção de redação da Folha de São Paulo, objetivando identificar a massa crítica dos envolvidos na produção de matérias sobre educação, além de procurar estabelecer uma análise do comportamento editorial do jornal nos diferentes momentos analisados.

O estudo faz referências às áreas da Educação e da Educomunicação, utilizando como autores Cláudio Abramo, Maria A. Baccega, Luiz Beltrão, Pierre Bourdieu, Adilson Citelli, Caio Túlio Costa, Paulo Freire, Mário Kaplún, e Ismar Soares.

A pesquisa finaliza apontando que, entre os períodos analisados, ocorreu uma diminuição na cobertura destinada pelo jornal à educação. Segundo o autor, este declínio é justificado pelo pouco interesse dos leitores por assuntos relacionados à educação, fato este atestado por pesquisas realizadas pelo próprio jornal. Afirma ainda que a pouca atenção dispensada por este veículo à educação é proporcional à atenção que o tema desperta na população brasileira.

Em 2009 foi apresentada ao Programa de Pós-Graduação em Educação da USP-SP a dissertação A centralidade da comunicação na socialização de jovens: um estudo sobre mediação escolar, de autoria de Rodrigo Pelegrini Ratier.

O trabalho investiga a relação de jovens estudantes com a comunicação. A hipótese é de que esses estudantes, imersos no consumo dos meios de comunicação e possuidores de um discurso crítico em relação a eles, encontram partilha, na mídia, com outras instituições socializadoras como a família, a escola e a religião, no eu diz respeito à formação de ideais, valores e modelos de conduta. A pesquisa busca avaliar em que medida a mediação escolar é efetiva, para que esses jovens estabeleçam com a mídia uma relação mais reflexiva.

O autor informa que, para examinar a hipótese apresentada, concebeu e ministrou um programa de comunicação e educação em 2007, para 31 alunos de uma escola pública do município de São Paulo. Nesse curso, pensado como instrumento promotor de uma aproximação e compreensão do universo simbólico e cultural do grupo analisado, foram produzidos materiais quantitativos e qualitativos que embasaram os resultados apresentados. Investigou-se a influência da escola como mediadora da relação entre jovens e mídia. A esse respeito, a hipótese é que a escola pode atuar como mediadora, no sentido de formar jovens mais maduros, críticos, ativos e criativos em relação à comunicação. 
O pesquisador utiliza autores que discutem temas relacionados à educação, à comunicação e à educomunicação, destacando-se Maria A. Baccega, Pierre Bourdieu, Bernard Charlot, Adilson Citelli, Paulo Freire, Jesús Martín-Babero, Guillermo Orozco-Gómez, e Ismar Soares.

O trabalho aponta, como relevante, a presença de um nível não desprezível de senso crítico e de capacidade questionadora nos jovens analisados. Indica o papel central que os meios de comunicação exercem na formação de valores e ideais em seus modelos de conduta. No entanto, essa centralidade não é exclusiva dos meios de comunicação. Segundo Ratier (2009), estes se articulam com outras instâncias como a família, a escola e a religião. Conclui que cursos como este, colaboram para ampliar as competências comunicativas dos alunos, tanto na dimensão da recepção, quanto na produção de produtos midiáticos.

\section{Conclusões}

Ao se avaliar o conjunto de teses e dissertações analisadas, é possível relacionar vários elementos que sinalizam suas principais tendências, identificadas nas linhas de pesquisa que discutem os campos da educação e da comunicação.

De início, ao trazer à discussão o tema "educação" para a mídia, percebe-se que uma questão que está fortemente enraizada nos debates que se processam em torno desta área, é o que se convencionou denominar educomunicação.

A implantação de processos educomunicativos, termo que a princípio designava apenas a leitura crítica dos meios e que aos poucos vem se ampliando para também nomear as ações que compõem o complexo campo da inter-relação educação-comunicação, está fortemente presente nos trabalhos que apresentam o rádio como importante elemento de comunicação.

Mais adiante, quando se buscou fazer uma análise da inserção dos recursos vídeotecnológicos na educação, esta questão novamente vem à tona, tornando-se fundamental para a discussão das implicações ideológicas e das possibilidades pedagógicas do cinema e, em especial, da televisão, nos processos educativos.

Apesar de não serem apresentadas experiências exitosas, como as que estão expostas nos projetos que analisam a educação através do rádio, percebe-se uma tendência em apontar para a necessidade de se discutir criticamente os produtos cinematográficos e televisivos, quando de sua inclusão em ações educativas.

Até mesmo a internet, ainda recente no cenário mundial, quando comparada a outras tecnologias de informação e comunicação já consolidadas, vem ganhando aportes da educomunicação. Os trabalhos que analisam as possibilidades de sua interface com a educação sinalizam para a importância de sua utilização em projetos educomunicativos. 
Quando se analisa os trabalhos que discutem o tema "mídia e meio ambiente", percebe-se que o debate envolve as estratégias utilizadas para a abordagem de temas relacionados a esta área, em veículos como televisão e jornais impressos. Alguns dos trabalhos analisados revelam uma forte tendência para a tentativa de manipulação das informações; consequentemente, há necessidade de uma maior preparação do leitor/espectador para uma recepção crítica dos produtos disponibilizados.

Uma avaliação dos trabalhos que discutem ciência e tecnologia na mídia permite concluir que está ocorrendo uma forte aproximação entre estas entidades, da mesma forma que já ocorre em relação às questões ambientais. Neste caso, tanto a ciência, a tecnologia, quanto os problemas relativos ao meio ambiente, parecem carecer de uma maior atenção quando de sua divulgação, pois o que os trabalhos detectam é que estes assuntos não recebem da mídia o tratamento adequado à sua real importância. Questões fundamentais, inerentes a estes campos, são expostas de maneira simplificada e sem grandes discussões, o que dificulta uma abordagem crítica e contextualizada sobre os mesmos.

Ao analisar a relação "mídia e educação", verifica-se o quanto é importante esta discussão para que se possa compreender como estes dois campos interagem e em que nível se processa a influência exercida pela mídia, quando utilizada em atividades educativas. Particularmente, neste tópico, verifica-se uma forte relação de proximidade com um estudo que está sendo desenvolvido pelo primeiro autor do presente artigo, no Programa de Pós-Graduação em Educação Científica e Tecnológica da Universidade Federal de Santa Catarina - UFSC, no qual é discutido o papel da mídia como instrumento de educação e de ampliação da consciência ambiental. Acredita-se que todas as questões levantadas nas teses e dissertações consultadas podem trazer contribuições significativas para a elaboração tanto dessa pesquisa como para futuros trabalhos, que estudem a imbricação desses importantes campos do conhecimento. São questões que se entrelaçam e se complementam, permitindo visualizar o que já vem sendo produzido e o que ainda se encontra em descoberto.

No contexto do ensino profissional, a discussão de processos educomunicativos, por exemplo, ainda se constitui num campo a ser amplamente explorado. Se existem experiências nesta área, essas ainda não têm sido debatidas ou divulgadas adequadamente, no meio educacional. É neste sentido que uma abordagem como a que se realiza neste artigo pode significar avanços consideráveis para, por exemplo, uma discussão crítica das questões que envolvem a formação técnica e tecnológica, em Institutos Federais de Ciência e Tecnologia.

Ao se montar um quadro conceitual como este, onde são analisados novos horizontes na relação "mídia-educação", ocorrem avanços no sentido de buscar compreender as reais interferências que os meios de comunicação exercem sobre os processos educativos. Busca-se, 
também, como isto pode ser utilizado para favorecer a compreensão e a ampliação de conceitos relativos às questões ambientais, bem como as implicações da ciência e da tecnologia sobre a sociedade, quando debatidas no âmbito de formações tão específicas, como as que se verificam em cursos técnicos e de tecnologia.

\section{Referências}

Alves, Patrícia Horta. Educom.Rádio: uma política pública em Educomunicação (tese). Doutorado em Ciências da Comunicação, Escola de Comunicação e Artes da USP, São Paulo, 2007.

Arruda, Denise Juliani. Imprensa e meio ambiente: as mudanças na cobertura jornalística entre a Rio 92 e a Rio+10 - o caso da Gazeta Mercantil (dissertação). Mestrado em Ciências da Comunicação, Escola de Comunicação e Artes da USP, São Paulo, 2006.

Baptistela, Cecília Fernandes. A concepção de pais e professores sobre a educação para a mídia (tese). Doutorado em Educação, Faculdade de Educação da Universidade Estadual de Campinas, São Paulo, 2009.

Consoni, Marciel Aparecido. Mediação tecnológica na educação: conceito e aplicações (tese). Doutorado em Ciências da Comunicação, Escola de Comunicação e Artes da USP, São Paulo, 2008.

Cordeiro, Mauro Soares. Política educacional, elaboração e continuidade: o programa Educom.Rádio nas escolas municipais da capital de São Paulo (dissertação). Mestrado em Educação, Faculdade de Educação da USP, São Paulo, 2009.

Cordeiro, Sandro da Silva. Televisão em solo educativo: educando olhar. (dissertação). Mestrado em Educação, Centro de Ciências Sociais Aplicadas da UFRGN, Rio Grande do Norte, 2006.

Cripa, Marcos Luiz. A cobertura da educação no jornal "Folha de São Paulo": uma análise comparativa nos anos de 1973 e 2002 (dissertação). Mestrado em Ciências da Comunicação, Escola Superior de Comunicação e Artes da USP, São Paulo, 2007.

Funari, Claudia Vicenza. A prática da mediação em processos educomunicacionais: o caso do projeto Educom.Rádio (dissertação). Mestrado em Ciências da Comunicação, Escola de Comunicação e Artes da USP, São Paulo, 2007.

Gilioli. Renato de S. Porto. Educação e Cultura no rádio brasileiro: concepções de rádio escola em Roquette-Pinto (tese). Doutorado em Educação, Faculdade de Educação da USP, São Paulo, 2008. Guido, Lucia de F. E. Educação televisão e natureza, uma análise do Repórter Eco (tese). Doutorado em Educação, Faculdade de Educação da UNICAMP, São Paulo, 2005. Junior, Renato Tavares. Educomunicação e expressão comunicativa: a produção radiofônica de crianças e jovens no Projeto Educom.Rádio (dissertação). Mestrado em Ciências da Comunicação, Escola de Comunicação e Artes da USP, São Paulo, 2007. 
Leão, Maria Izabel de A. O papel da internet nos projetos educomunicativos do NCE/USP. (dissertação). Mestrado em Ciências da Comunicação, Escola de Comunicação e Artes da USP, São Paulo, 2008.

Lestinge, Roberto. A visão da ecologia no Jornal Nacional (dissertação). Mestrado em Ecologia Aplicada, Escola Superior de Agricultura “Luiz de Queiroz. da USP, São Paulo, 2008.

Lima, Gracia Lopes. Educação pelos meios de comunicação: produção coletiva da comunicação (tese). Doutorado em Educação, Faculdade de Educação da USP, São Paulo, 2009.

Lückman, Ana Paula. Educação, jornalismo e meio ambiente: leitura sobre a crise ecológica no contexto do aquecimento global (dissertação). Mestrado em Educação, Centro de Ciências da Educação da UFSC, Santa Catarina, 2007.

Mauro, Fabiana. Mensagens sobre a natureza: um estudo de duas revistas de turismo (dissertação). Mestrado em Ecologia de Agroecossistemas, Escola Superior de Agricultura "Luiz de Queiroz" da USP, São Paulo, 2005.

Martni, Rafael Gué. Educação e comunicação em ambiente associativo: web site como um dispositivo de educomunicação (dissertação). Mestrado em Educação, Centro de Ciências da Educação, Faculdade de Educação da UDESC, Santa Catarina, 2009.

Martins, Juliane. Educação para a divulgação científica: o professor pesquisador e a relação comunicação, ciência e sociedade (dissertação). Mestrado em Educação da PUC, Paraná. 2006. Miranda, Amanda S. de. Divulgação cientifica e educomunicação (dissertação). Mestrado em Educação Científica e Tecnológica, Centro de Ciências da Educação da UFSC, Santa Catarina, 2007. Mota, Rosimar Ramos da. $O$ uso pedagógico das tecnologias de vídeo e televisão: análise do programa TV Escola no município de Tubarão - SC (dissertação). Mestrado em Educação e Cultura, Faculdade de Educação da UDESC, Santa Catarina, Santa Catarina, 2005.

Peinado, Carlos E. D. A internet na construção do conhecimento: a importância das mediações (dissertação). Mestrado em Educação, Universidade do Oeste Paulista - UNOESTE, São Paulo, 2007.

Pereira, Silvio da Costa. Mídia-educação no contexto escolar: mapeamento crítico dos trabalhos realizados nas escolas de ensino fundamental em Florianópolis (dissertação). Mestrado em Educação, Centro de Ciências da Educação da UFSC, Santa Catarina, 2008.

Pinel, Neiva B. M. Educação, Internet e suas interações com o sujeito: o desafio do contexto escolar (dissertação). Mestrado em Educação, Universidade Católica do Paraná, Paraná, 2007. 
Ramos, Mariana Brasil. Discurso sobre ciência e tecnologia no Jornal Nacional (dissertação). Mestrado em Educação Científica e Tecnológica, Centro de Ciências da Educação da UFSC, Santa Catarina, 2006.

Ratier, Rodrigo Pelegrini. A centralidade da comunicação na socialização de jovens: um estudo sobre mediação escolar (dissertação). Mestrado em Educação em Educação, Faculdade de Educação da USP, São Paulo, 2009.

Ruaro, Laurete Maria. Educação para e com a mídia - análise da utilização das tecnologias da informação e comunicação na rede pública de educação: Programa Paraná Digital (dissertação). Mestrado em Educação, Universidade Católica do Paraná, Curitiba, 2007.

Segawa, Francine Sayuri. Programa Educom.Rádio: um estudo sobre representações (dissertação). Mestrado em Educação, Faculdade de Educação da USP, São Paulo, 2009.

Seligman, Laura. A escola e a formação do leitor crítico da mídia: políticas no Brasil e em Santa Catarina (dissertação). Mestrado Acadêmico em Educação, UNIVALI, Santa Catarina, 2008.

Silva, Marcio José da. $\mathbf{O}$ ensino de CTS através de revistas de divulgação científica (dissertação). Mestrado em Educação Científica e Tecnológica, Centro de Ciências da Educação da UFSC, Santa Catarina, 2005.

Siqueira, Juliana Maria. Quem educará os educadores? A educomunicação e a formação de docentes em serviço (dissertação). Mestrado em Educação, Escola de Comunicação e Artes da USP, São Paulo, 2009.

Sommerhalder-Mike, Helenita. Oficina de TV, uma prática educomunicativa: estudo de caso de uma criança abrigada (dissertação). Mestrado em Psicologia, Departamento de Psicologia e Educação da USP, São Paulo, 2008.

Sousa, Bruno Jorge. 0 cinema na escola: aspectos pedagógicos do texto cinematográfico (dissertação). Mestrado em Educação, Universidade Católica de Goiás, Goiás, 2005.

Fernando Teixeira. Instituto Federal de Educação. Professor do Curso de Meio Ambiente do Instituto Federal de Educação, Ciência e Tecnologia de Santa Catarina - IFSC. Doutorando do Programa de Pós-Graduação em Educação Científica e Tecnológica da UFSC.

fernando@ifsc.edu.br.

Vivian Leyser da Rosa. Universidade Federal de Santa Catarina (UFSC). Professora Associada do Departamento de Biologia Celular, Embriologia e Genética do Centro de Ciências Biológicas na UFSC. Professora do Programa de Pós-Graduação em Educação Científica e Tecnológica na UFSC. Doutora em Educação (UFSC). vivian@ced.ufsc.br

R. B. E. C. T., vol 4, núm 2, mai./ago. $2011 \quad$ ISSN - 1982-873X 